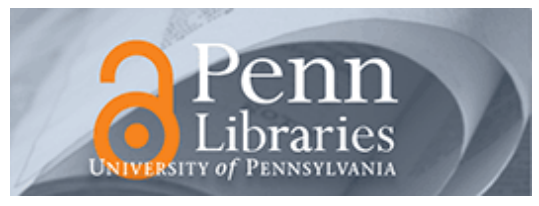

University of Pennsylvania

ScholarlyCommons

Marketing Papers

Wharton Faculty Research

2008

\title{
Who Drives Divergence? Identity Signaling, Outgroup Dissimilarity, and the Abandonment of Cultural Tastes
}

Jonah A. Berger

University of Pennsylvania

Follow this and additional works at: https://repository.upenn.edu/marketing_papers

Part of the Marketing Commons

\section{Recommended Citation}

Berger, J. A. (2008). Who Drives Divergence? Identity Signaling, Outgroup Dissimilarity, and the Abandonment of Cultural Tastes. Journal of Personality and Social Psychology, 95 (3), 593-607. http://dx.doi.org/10.1037/0022-3514.95.3.593

This paper is posted at ScholarlyCommons. https://repository.upenn.edu/marketing_papers/205

For more information, please contact repository@pobox.upenn.edu. 


\title{
Who Drives Divergence? Identity Signaling, Outgroup Dissimilarity, and the Abandonment of Cultural Tastes
}

\author{
Abstract \\ People often diverge from members of other social groups: They select cultural tastes (e.g., possessions, \\ attitudes, or behaviors) that distinguish them from outsiders and abandon tastes when outsiders adopt \\ them. But while divergence is pervasive, most research on the propagation of culture is based on \\ conformity. Consequently, it is less useful in explaining why people might abandon tastes when others \\ adopt them. The 7 studies described in this article showed that people diverge to avoid signaling \\ undesired identities. A field study, for example, found that undergraduates stopped wearing a particular \\ wristband when members of the "geeky" academically focused dormitory next door started wearing them. \\ Consistent with an identity-signaling perspective, the studies further showed that people often diverge \\ from dissimilar outgroups to avoid the costs of misidentification. Implications for social influence, identity \\ signaling, and the popularity and diffusion of culture are discussed. \\ Disciplines \\ Business | Marketing
}




\title{
Who Drives Divergence?
}

\section{Identity-Signaling, Outgroup Dissimilarity, and the Abandonment of Cultural \\ Tastes}

\author{
Jonah Berger \\ Chip Heath \\ University of Pennsylvania \\ Stanford University
}

Forthcoming, Journal of Personality and Social Psychology

Correspondence:

Jonah Berger

700 Jon M. Huntsman Hall

3730 Walnut Street

University of Pennsylvania

Philadelphia, PA 19104-6304

Phone: 215-898-8249

Email: jberger@wharton.upenn.edu 


\begin{abstract}
People often diverge from members of other social groups: they select cultural tastes (e.g., possessions, attitudes, or behaviors) that distinguish them from outsiders and abandon tastes when outsiders adopt them. But while divergence is pervasive, most research on the propagation of culture is based on conformity. Consequently, it is less useful in explaining why people might abandon tastes when others adopt them. Seven studies demonstrate that people diverge to avoid signaling undesired identities. A field study, for example, found that undergraduates stopped wearing a certain wristband when members of the geeky academic focus dorm next store started wearing them. Consistent with an identity-signaling perspective, the studies further demonstrated that people often diverge from dissimilar outgroups to avoid the costs of misidentification. Implications for social influence, identity signaling, and the popularity and diffusion of culture are discussed.
\end{abstract}

Keywords: Culture, Diffusion, Identity, Social Influence, and Intergroup Processes 
Kids abandon clothing styles that are adopted by their parents and jocks dump catchphrases that are picked up by geeks. Shanghai residents stopped purchasing Volkswagen Santanas when nouveaux rich suburbanites started buying them (Wonacott, 2004) and rich Brits abandoned Burberry caps once they caught on among soccer hooligans (Clevstrom \& Passariello, 2006). Original members of any cultural scene (i.e. music, style or philosophical schools) want to signal that they are different from the poseurs that come along later. The social process that underlies all these examples is one of divergence, by which we mean that people select cultural tastes (e.g., attitudes, possessions, and behaviors) that distinguish themselves from members of other groups, and they abandon cultural tastes when members of other social groups adopt them. Divergence is pervasive in social life.

Recent research has highlighted the value of studying psychological factors that influence the transmission and success of culture (Berger \& Heath, 2005; Lyons \& Kashima, 2003; McIntyre, Lyons, Clark, \& Kashima, 2004; Norenzayan, Atran, Faulkner, \& Schaller, 2006; Schaller \& Crandall, 2004; Schaller, Conway, \& Tanchuk, 2002), but less research has examined why culture might be abandoned. While divergence is quite pervasive, most research has focused on convergence. One of the most widely discussed principles in social psychology is conformity (e.g., Asch, 1956; Sherif, 1936). Similar tendencies have been recognized under different names by researchers in sociology (e.g., mimetic isomorphism, DiMaggio \& Powell, 1983) and economics (e.g., herd behavior, Banerjee, 1992).

Because models of the diffusion of innovations and cultural tastes and practices (e.g., Bass, 1969; Rogers, 1983) are implicitly based on conformity dynamics, they are 
less helpful in understanding why people might abandon tastes. These models suggest people should be more likely to engage in a behavior the more others that are doing so. Dynamic Social Impact Theory (Latane, 1996), for instance, predicts that people will become more similar to those around them and that their attitudes will become increasingly correlated over time (e.g., Harton \& Bourgeois, 2004). But while conformity processes are obviously important, they predict convergence, and thus cannot account for a world in which people select tastes that distinguish themselves from others and abandon tastes that are adopted by other social groups.

Further, although the divergence in cultural tastes we study can be considered a form of intergroup differentiation, it is a type of differentiation that has not been frequently considered in the rich intergroup tradition in social psychology. Previous work on intergroup differentiation has focused primarily on processes such as prejudice (e.g., White \& Langer, 1999) and intergroup conflict (e.g., Tajfel \& Turner, 1979). The behaviors typically used to measure these processes include resource allocation (e.g., Moghaddam \& Stringer, 1988), evaluations (e.g., Roccas \& Schwartz, 1993), and trait ratings (e.g., Brown \& Abrams, 1986), mostly in the context of trying to understand when and why people tend to favor their own group. For the most part, this research has not studied differences in cultural tastes, though such differences are pervasive in social life and are worth trying to explain psychologically. We know people diverge, but why?

\section{Who Drives Divergence and Why?}

Though it has not focused on the abandonment of cultural tastes, existing research can be used to make predictions about why people diverge. Each research stream, however, has difficulty explaining certain classes of divergence. 


\section{Divergence Driven By Low Status Others}

Sociologists agree that individuals want to set themselves apart from members of other social categories (e.g., DiMaggio, 1982; Simmel, 1904 [1957]), but they have primarily focused on processes in which groups with traditionally high status (e.g., wealthy, educated) groups diverge from traditionally low status adopters. This literature is based on the trickle down theory of fashion (e.g., Robinson, 1961), which suggests that people adopt from those above them in the status food chain. Fashions are initiated by higher status people and imitated by people with lower status. But, once the lower strata have adopted, the signal value is lost and high status people abandon the taste. Similarly, experimental work finds people diverge, or are less likely to endorse behaviors supported by low status others (Cohen \& Prinstein, 2006).

Many examples of taste abandonment, however, are not easy to classify in terms of a unidimensional status ordering. Teenagers reject catchphrases once they creep into the lexicon of their parents who probably occupy a higher social status. And rather than unidirectional imitation and abandonment, different racial groups work hard to diverge from each other: just as whites selected names to distance themselves from blacks in the early 1900s (London \& Morgan, 1994), blacks often abandon clothing styles or slang that are adopted by whites. Fashion does not solely originate among the upper classes (Davis, 1992), and, in fact, often arises in low-status or somewhat marginalized groups (e.g., inner city teens or homosexual men; see Berger, in press, for a potential explanation). This suggests that divergence is driven by more than just unidimensional status.

\section{Divergence Driven by Disliked Others}


Other work might predict that people diverge from people they dislike. People increase their association with groups they view positively (Cialdini, et. al., 1976) and thus it follows that they might be driven to decrease association with others they view negatively. Indeed, people use music tastes to reinforce boundaries between them and groups they dislike (Bryson, 1996), shift their attitudes away from obnoxious others (Cooper \& Jones, 1966), and distance themselves from groups with negative traits (Jackson, Sullivan, Harnish, \& Hodge, 1996). This prediction can also be derived from work on balance theory (e.g., Heider, 1946): If a disliked other (or group) likes a certain cultural taste, people should be more likely to dislike that taste themselves.

But while liking may play some role in why people abandon tastes, people often diverge from liked groups. Kids may like their parents a lot, but diverge when parents adopt their slang or way of dress. Newly minted professors like their friends who are still graduate students, but they no longer want to dress like one. Affect based accounts also have difficulty explaining why people sometimes adopt or accentuate seemingly negative traits as a way to achieve differentiation. Polish students considered it important that others correctly identify their national identity and listed traits like quarrelsome, vulgar and disorderly as those most typical of Poles (Milicki \& Ellmers, 1996). These factors suggest that divergence is driven by more than just liking.

\section{Divergence Driven by Similar Others}

A great deal of literature, including work on uniqueness (e.g., Snyder \& Fromkin, 1980), optimal distinctiveness (e.g., Brewer, 1991), and intergroup differentiation (e.g., Spears, Jetten, \& Scheepers, 2002; see Jetten, Spears, \& Postmes, 2004 for a metaanalytic review), would predict that people diverge from others that are similar. 
Literature on individual drives for differentiation suggests people would diverge as a result of too much similarity. The uniqueness literature (e.g., Snyder \& Fromkin, 1980; Lynn \& Snyder, 2002) argues that people have a drive to be unique, and that too much similarity leads to a negative emotional reaction. Consequently, this literature would predict that people might diverge from extremely similar others because their adoption of a taste could lead original taste-holders to feel overly similar. Optimal Distinctiveness Theory (ODT, e.g., Brewer, 1991) suggests that people reconcile opposing needs for assimilation and differentiation through their group memberships. When people feel overly similar, they strive to differentiate themselves. Applied to divergence, it would predict that people should diverge due to feelings of too much similarity. Importantly, both the uniqueness literature and ODT conceive the need for distinctiveness as a personal drive, operating at the individual level.

Research on intergroup differentiation focuses on more group-level process and perceptions of intergroup difference rather than individual drives, but it also argues that people will differentiate themselves from similar others (Brown \& Abrams, 1986; Jetten \& Spears, 2003; Mummendey \& Schreiber, 1984; Tajfel, 1982; Turner, 1978). Similar outgroups are relevant for social comparisons, but they also threaten the distinctiveness of the ingroup. Consequently, when people are confronted by extremely similar groups they show more horizontal hostility (White \& Langer, 1999), allocate more rewards to ingroup members (Moghaddam \& Stringer, 1988), and show ingroup bias in evaluations (Roccas \& Schwartz, 1993). This cluster of behaviors has been described as reactive distinctiveness (Spears, et al., 2002; Jetten, et al., 2004), and has been explained using social identity theory as a product of too much intergroup similarity. 
These diverse literatures would suggest that similarity drives divergence, yet people also often diverge from groups that are dissimilar. Los Angeles residents may keep wearing a clothing style that is adopted by people from San Francisco, but they may be more likely to abandon it if adopted by residents of Des Moines. In these situations, groups diverge more strongly when the adopting groups are dissimilar. Because uniqueness and optimal distinctiveness predict greater divergence from people we feel overly similar towards, and because work examining intergroup differentiation on behavioral measures finds greater differentiation from similar others (e.g., Jetten, et al., 2004), these perspectives are less suited to explain why people might abandon tastes that are adopted by others that are dissimilar.

\section{An Identity-Signaling Approach to Divergence}

We propose an identity-signaling approach to divergence. Our perspective focuses on how distinguishing groups from one another can provide meaning (Abrams \& Hogg, 1988; Bourdieu, 1984; Simmell, 1957). However, instead of assuming people diverge to better understand their place in the social environment, or reduce their own internal uncertainty about who they are (e.g., Hogg, 2000), we suggest people diverge to ensure that others understand who they are. In particular, people often diverge to avoid sending undesired identity signals to others.

We define a signal as a compact indicator of some set of information that is hard to observe or hard to summarize. When we first meet a group of people, for instance, we may want to know "who I would enjoy getting to know?", and we may use their clothing, vocabulary, or cultural references to decide whom to interact with further and how to treat them during that interaction (e.g., Wernerfelt, 1990). Signals can be extremely easy 
to detect, like whether someone has a pierced nose, or more difficult, like whether they correctly use phrases like hegemonic discourse or self-regulatory process.

Across the social sciences, researchers suggest that cultural tastes act as signals or markers within the social communication system, communicating aspects of people (e.g., the social groups they belong to or other preferences they hold) to others (e.g., Davis, 1992; Douglas \& Isherwood, 1978). Attitudes and products can serve a symbolic function (e.g., Shavitt, 1990) and a great deal of research finds that people infer things about others based on their cultural tastes (see Belk, Bahn, \& Mayer, 1982 for an overview). One might posit that a Birkenstock wearer supports liberal politics or that a Harley Davidson rider prefers beer to wine.

Tastes communicate identity through their association with groups, or types of individuals (Escalas \& Bettman, 2005), but if they are adopted by outsiders the taste may lose its ability to signal desired characteristics effectively (e.g., Thorton, 1996). If lots of tough people ride Harley motorcycles, then Harleys may come to signal that rugged identity. But if suburban accountants start riding Harleys in an attempt to seem tough, the meaning of the taste may shift. It will likely become diluted and lose its value in distinguishing between groups or it may come to signal entirely different characteristics (wannabe tough guys). Original taste holders may then abandon the taste to avoid signaling an undesired, or unclear, identity (e.g., Hebdige, 1987).

We assume that people diverge, at least in part, to ensure their identity is correctly recognized by others. Uniqueness and optimal distinctiveness have primarily focused on internal manifestations of internal drives for difference (though see Pickett, et al. 2002, Study 3). Similarly, SCT has focused on internal motivations for intergroup 
differentiation - self-esteem, or self-enhancement (for reviews, see Rubin \& Hewstone, 1998; Vignoles, et al, 2000). In the divergence examples mentioned previously, however, people seem to be abandoning tastes not for internal reasons, but for social concerns about how others might see them. It is unclear how abandoning something one previously liked could increase self-esteem, and it's plausible that people diverge not because they are in the process of defining themselves, but because they already have a clear selfdefinition and want to ensure it is correctly communicated to others. Shanghai residents don't abandon Volkswagen Santanas to make themselves feel better, or because they are grappling to understand their own self-definition, they do so to avoid others treating them liked they are a member of the nouveaux riche.

Importantly, people often diverge to ensure that they send appropriate signals about complex identities that involve subtle social characteristics, rather than group identities per se. Most people aren't going to confuse a CEO with a teenager, a woman with a man, or a balding accountant with a grizzled Harley rider. Yet if business executives start saying a teenage catchphrase or accountants start wearing biker jackets, others who see someone with those tastes may be more likely to infer that they share characteristics with those groups. Indeed, men were less likely to choose a $10 \mathrm{oz}$. steak when it was labeled as a "ladies cut," especially when they thought others would see their choice (White \& Dahl, 2006). It is unlikely that they thought that others would think they were female, but they may have avoided choosing that steak because doing so would make others think they were less masculine. Thus people may abandon tastes adopted by other social groups to avoid signaling their characteristics.

Divergence Driven by Identity-Signaling Concerns 
Our identity-signaling approach suggests that the cost of misidentification should lead people to diverge most strongly when their cultural tastes are adopted by others who are dissimilar. Misidentification has a variety of costs and prior work has often discussed internal ones. Work on self-verification, for example, has emphasized that people want to see themselves a certain way, and when others treat them differently, it threatens the stability and coherence of their self-view (Swann, 1983). Similarly, being mistaken for a member of another group may lead to psychological costs of feeling like an imposter.

This paper, however, focuses on costs that are more social or external. Cultural tastes make it easier to find people we want to interact with. People look for friends with particular interests and mates with certain characteristics, and they use others' tastes to determine who to approach. The pleasure or pain of social interactions can differ depending on how well a signal helps people to find these others.

When dissimilar others adopt cultural practices, the signaling process breaks down and social interactions become less satisfying and sometimes even painful. Wearing a heavy metal t-shirt, for example, may facilitate interactions with people who like heavy metal. But if fashionistas start wearing heavy metal t-shirts because they look good with black jackets, the t-shirts will no longer be an effective signal. Consequently, true metal heads who wear such t-shirts may be ignored by desired mates and potential friends. Heavy metal fans may stop approaching others wearing the t-shirts because they are now unsure whether the wearer cares about guitar riffs or Prada's spring collection. Misidentification is costly because it leads people to miss out on desired interactions and interaction partners and get stuck interacting with undesired ones. 
Since dissimilar others are less likely to share identity-relevant traits, people should be more motivated to diverge when dissimilar others adopt their tastes. If Stanford students wear Reef flip flops to signal their casual, outdoorsy approach to life, then adoption of Reefs by similar students at UC-Santa Cruz probably won't have much effect because Santa Cruz students share a similar casual, outdoorsy approach. But if a dissimilar group like business executives adopt the flip flops, then that footwear loses its ability to clearly signal the original identity-relevant traits. Business executives spend a lot of their lives indoors and have anything but a casual approach to life. As a result the original taste-holders may diverge to avoid attracting social encounters with wrongminded people and missing out on desired encounters with right-minded ones.

If people do diverge more from social groups that are dissimilar, this suggests that something beyond current theories of differentiation may be driving the divergence process. Some prior research has acknowledged that differentiation may occur when intergroup similarity is low, but researchers have focused on a form of differentiation that is much more passive and perceptual (reflective distinctiveness, Spears, et al. 2002; Jetten et al, 2004). When groups are already quite different, people can just note the existing differences (e.g., "we are taller") rather than actively creating them.

Divergence behaviors, however, suggest that people respond to dissimilar groups in a way that is not limited to passive perceptual acknowledgement of differences. If LA residents abandon tastes adopted by people in Des Moines, they are not merely reflecting existing differences, they are diverging to maintain or create new ones. People could achieve self-esteem and self-definition just by noting the existing differences with dissimilar groups. Why do they pay the personal costs of abandoning tastes that they once 
liked? While existing theories of differentiation go far in explaining some forms of differentiation, they are less suited to explain why people diverge in their cultural tastes.

\section{Overview of the Present Research}

We suggest that people often abandon identity-relevant cultural tastes that are adopted by outgroup members. Further, our identity-signaling perspective predicts that people will be more likely to abandon a taste when it is adopted by dissimilar others.

In Study 1, we investigate whether it is indeed more costly to be misidentified as a member of dissimilar groups. The next six studies then examine divergence based on the similarity of the adopting group to the current taste holders. Study 2 looks at whether people will abandon a wristband if it is adopted by a dissimilar social group, the "geeks" next door. To underscore the role of social signaling, Study 3 examines whether people are more likely to diverge from dissimilar others when behavior is public. Study 4 uses a range of social groups to examine the influence of outgroup similarity on taste change. Study 5 investigates whether the cost of misidentification mediates the relationship between outgroup similarity and divergence. In Study 6, we build on research showing that people diverge more in domains of life that are identity-relevant (e.g., cars and clothes) to illustrate that both the domain and outgroup similarity moderate divergence. Finally, Study 7 examines a broad range of outgroups and further tests whether theses effects are mediated by the cost of misidentification.

\section{Study 1: Costs of Misidentification}

Before examining divergence, we first wanted to test our suggestion that it is more costly to be misidentified as a member of a dissimilar social group. We gave people 
a list of social groups, and asked them how much being misidentified as a member of each group would help or hurt their ability to meet potential interaction partners. Separate sets of raters also rated the groups on similarity and liking. We predict that outgroup similarity will influence the cost of misidentification; even controlling for how much people like the group, people will perceive it to be more costly to be misidentified as a member of a dissimilar social group.

\section{Method}

\section{Participants and Procedure}

Fifty-three Stanford students were given a list of different social groups (e.g., 40 year old business executives, Princeton students, suburban teens, 15 in total) and asked to rate them on one of three dimensions. One set of raters $(\mathrm{N}=16)$ were asked to imagine that others thought they shared identity-relevant traits with members of each group and rated the costs of such misidentification ("Would it help or hurt your ability to meet potential romantic partners?", Would it help or hurt your ability to meet people you want to be friends with?", $1=$ Hurt a lot, $7=$ Help a lot, $\alpha=.70$ and .86 respectively across raters). The two measures were highly correlated $(\mathrm{r}=.96)$ and averaged to form an index of misidentification cost. Separate sets of participants also rated the groups on our predictor variables, i.e., similarity $(\mathrm{N}=20$, "How similar do you think you and your Stanford friends are to the various types of people below?", $1=$ Not very similar, $7=$ Very similar, $\alpha=.76)$ or liking $(\mathrm{N}=17$, "How positive or negative do you feel about each of the types of people below?", $-3=$ Very negative, $3=$ Very positive, $\alpha=.91$ ). 


\section{Results}

Each set of ratings was averaged across the various raters to create a misidentification cost, similarity, and liking score for each social group. A multiple regression analyzed the cost of misidentification as a function of outgroup similarity and how much they were liked. Consistent with prior research, there was some effect of liking, though it did not reach significance, $\beta=.19, p=.25$; people preferred not to be thought of as part of groups they disliked. Even when controlling for liking, however, analysis revealed the predicted significant effects of similarity, $\beta=.76, t(14)=4.65, p<$ .001 ; people preferred not to be thought of as members of dissimilar groups.

\section{Discussion}

The results of the first study support the notion that outgroup similarity influences the cost of misidentification. It is more costly to be misidentified as a member of dissimilar social groups. This effect occurs even when controlling for how much people like the group.

The first study is supportive, but will people actually abandon tastes that are adopted by a dissimilar social group? Study 2 examines this possibility.

\section{Study 2: Taste Abandonment - Don't Think of Me as One of Them}

Will people actually abandon a taste if it is adopted by an outgroup with which they do not want to be confused? Study 2 examines abandonment of a real cultural product, yellow Livestrong bands (Figure 1). In 2004, the Lance Armstrong Foundation sold these wristbands to support cancer awareness and research. The bands were originally worn by athletes, but later spread contagiously in the general public (Walker, 
2004). During the upswing of this trend, we distributed these bands to various university dorms to examine how adoption by dissimilar others might affect abandonment.

We sold wristbands to one dorm (Target dorm) and after a week delay, sold the same bands to an outgroup that was dissimilar (i.e., Academic Focus dorm next door). Members of the Target dorm did not dislike Academic dorm members (as evidenced by liking ratings) but at the same time, they did not want to be misidentified as a member of this group. Academic dorm members ended up in that dorm because they had requested taking part in extracurricular academic activities, and had a reputation for being the campus "geeks." A separate set of experimenters measured the number of Target dorm members who wore the wristband before and after it was adopted by the geeks. We predicted that when dissimilar others (i.e. Academic dorm members) adopted the wristband, members of the Target dorm would abandon it.

We also included a control condition to test boredom as a possible alternative explanation. Some theories of fads and fashions suggest people may abandon tastes because they just "get tired of them" (Sproles, 1985). To test this alternative, we also sold wristbands to a control population on the other side of campus and measured their usage of the taste over time. While Target dorm members should have frequent opportunities to see that the wristbands have been adopted by the geeks (they live in the same larger building, eat in the same dining hall, etc.), this was not the case for control participants. Boredom, however, should be the same for both groups.

\section{Method}

Wristband Distribution 
Research assistants went door to door in dorms at Stanford University, handing out yellow flyers with information about cancer, and selling yellow Livestrong wristbands to raise cancer awareness (Time 1, Figure 1). Experimenters informed students that it was "Wear Yellow" month at the school and asked students to wear yellow in the upcoming weeks to show their support for cancer awareness. In addition, students were asked if they would like to donate a dollar to the Lance Armstrong Foundation in exchange for a yellow wristband. Almost everyone agreed to donate, and the donations ranged from $\$ 0.25$ to $\$ 5.00$. Students were then given a wristband and asked to wear it to show their support for cancer awareness. Wristbands were sold to the same number of people (38) in the Target and control dorms, and the bands were sold to these groups on the same evening. ${ }^{1}$

A week later, the same assistants used the same procedure to sell a similar number of bands (36) to members of the Academic dorm (Time 3, Figure 1). This dorm takes part in extra academic activities (e.g., group discussions, extra courses) and had a reputation for being somewhat "geeky." The dorm was directly across a courtyard from the Target dorm, and the dorms were part of a larger residence which ate in the same dinning hall. Measurement of Wristband Wearing

As part of an ostensibly unrelated survey, different research assistants measured the number of people in both the Target and Control dorms that were wearing the wristband, both 6 days (Time 2, before the bands had been sold to the "geeks") and 13 days (Time 4, after the bands had been sold to the "geeks," Figure 1) after the wristbands had been originally sold. Staff in each dorm had agreed to have their residents complete a longitudinal "Attitude and Ownership" survey as part of an undergraduate's honors 
thesis. Dorm residents completed the survey at their house meeting on two consecutive weeks and received pizza as compensation. Research assistants also followed up with residents who did not attend the meeting and asked them to complete the survey.

\section{Questionnaire}

Students were told the researchers were "interested in student attitudes, the things students own, and how attitudes change over time." As filler, they were first asked to complete general behavior items (e.g., how often do you eat in the dining hall). Participants then rated liking and similarity (using the scales from Study 1) towards members of a number of other campus dorms, including the Academic dorm.

Our key dependent variable (wristband wearing) was embedded in a number of items on the back of the sheet. Participants were asked how frequently they engaged in certain cause related behaviors (e.g., attended a cause related rally) or wore different cause related items (e.g., breast cancer ribbon) including a Livestrong wristband. For each item, students were asked whether they had worn it in the past two days.

\section{Results}

\section{Group Liking and Similarity}

As expected, members of the Target dorm did not dislike members of the Academic dorm $(\mathrm{M}=.08$, not different from the scale midpoint $)$ but they did find them to be dissimilar. Similarity ratings for the Academic dorm were significantly below the midpoint of the 7-point scale $(\mathrm{M}=3.0), t(37)=4.09, p<.001$, and significantly lower than ratings for other dorms $(\mathrm{M}=4.31), t(37)=6.01, p<.001$. 


\section{Taste Abandonment}

Members of the Target dorm viewed the Academic dorm as dissimilar, but would they abandon a previously held taste when the geeks adopted it? Results suggest they did; in the week after the wristbands were adopted by the "geeks" there was a $32 \%$ drop in the number of Target dorm members who reported wearing the wristband. This drop is not accounted for by simple boredom. During the same period of time, there was only a $6 \%$ drop in wristband wearing in the control condition, $\chi^{2}(1, \mathrm{~N}=36)=3.78, p=.05$.

\section{Discussion}

The results of Study 2 illustrate that people may abandon cultural tastes that are adopted by other social groups. Students stopped wearing Livestrong wristbands once they had been adopted by the "geeky" dorm next store.

These results allow us to test a couple of alternative explanations. It is difficult to suggest people abandoned the wristband just because they were bored. Compared to the control, more people in the Target dorm abandoned the wristband, even though both groups had an equal chance to become bored with it. These results also do not seem to be driven by liking. Target dorm members did not dislike the members of the Academic dorm, they just thought they were dissimilar.

As with most field studies conducted, however, there are alternative explanations for the data. Though sharing one taste with 30 people is a much smaller manipulation than what is traditionally used in uniqueness experiments (e.g., $80 \%$ similarity to 10,000 students on 30 attitude items, Ganster, McCuddy \& Fromkin, 1977), one could argue that simply seeing more students wearing the wristband made it seem less unique, and thus uniqueness concerns drove the effects. In addition, though we used an outgroup rated as 
dissimilar, because we only used one group, we cannot definitively conclude that it was the dissimilarity of that group that drove our results. To address such concerns, the next study varies the similarity of the adopters to the current taste holders. This allows us to more directly assess the relationship between similarity and taste abandonment.

\section{Study 3: The Role of Public versus Private Behavior}

Study 3 examines the role of public behavior in divergence. Optimal distinctiveness argues that internal needs for distinctiveness lead people to differentiate themselves (Brewer, 1991; similar notions are discussed in the uniqueness literature, e.g., Snyder \& Fromkin, 1980). Though most of this literature has focused on private, internal methods of differentiation (e.g., personal valuation of identities or perceptions of group size), a recent study found that a manipulation that increased the need for differentiation not only led to private changes in trait ratings, but also led people to change the way they presented themselves to others (Picket et al., 2002, Study 3). Thus the ODT literature makes clear that people have a various internal ways to achieve dfferentiation, and that sometimes those carry over and affect public presentation.

In contrast, identity signaling does not require that private differentiation accompany public divergence. Because identity signaling is driven by social communication, it suggests that situations which induce public divergence, may, but do not necessarily, have effects on private behavior. Jocks would not want others to see them listening to music that geeks have adopted, but if they really liked a geek-adopted artist they might continue to listen secretly in private. Thus to the degree that divergence is 
driven by concerns of social communication, there may be instances where people diverge in public but not in private.

To test this possibility, Study 3 used a choice domain where we thought that private preferences might diverge from public behavior: junk food. ${ }^{2}$ Junk food is carefully engineered to tap into physiological desires for fatty foods laden with salt or sugar, thus it should be relatively attractive in terms of private preferences. Nonetheless, depending on the social group associated with junk food, people might diverge in public consumption away from what their private preferences would dictate. By using a real choice situation in which participants actually took home one of the options they chose during the experiment, the study also further examines actual behavioral divergence.

Undergraduates were exposed to information that linked junk food consumption with either similar others (other undergraduates) or dissimilar others (graduate students). To compare these conditions to normal behavior, some participants also participated in a control condition which did not link any group to junk food. Later, in the context of an ostensibly unrelated experiment, participants made a number of real food choices (e.g., Coke vs. Pepsi) in a pseudo-store environment. Some of the choice pairs involved junk food (e.g., apple vs. brownie). Further, while some of the participants made their choices in private, other participants made their choices in full view of other participants (public condition). Identity-signaling predicts that divergence may occur in public, even when it does not occur in private; that is, participants may choose less junk food when it is associated with a dissimilar outgroup, but only when their behavior is visible to others. 


\section{Method}

Seventy-six undergraduates completed two ostensibly unrelated studies as part of a larger session. They were randomly assigned to condition and run in small groups.

Participants first completed a "Writing Styles" survey as part of a larger packet of studies. They were asked to read three articles seemingly taken from an online version of the school newspaper, and respond with their thoughts about the article and the topic it covered. In the two main conditions, the middle article concerned junk food consumption on campus. The article suggested that certain students consumed the most junk food, and the only difference between conditions was the type of students mentioned. In the similar [dissimilar] others condition, participants read that:

"A recent survey of campus eating habits found that undergraduates [graduate students] are by far the largest consumers of junk food on campus. While eating habits among all campus groups could be healthier, the survey found that the average undergraduate [graduate student] consumes almost two times the amount of junk food as an average person on campus."

Graduate students in particular were selected as the dissimilar others because pilot data indicated that among a variety of campus groups, undergraduates liked graduate students but saw them as dissimilar to them and their friends. ${ }^{3}$ There was also a control condition in which the middle article was unrelated to junk food (i.e. commencement planning). After completing unrelated filler surveys, participants went down the hall to do the next (ostensibly unrelated) study with a different experimenter.

The second study examined food choice. The study room was set-up to mimic a shopping or dining hall environment and various products (e.g. Coke, granola bars, and 
brownies) were set up on different tables with a large number of each available.

Participants were asked to pick up a shopping basket and go around the room and select the options they preferred. They were told that they would be given one of the options they selected to take home. They key dependent variable was choice of junk food. Participants chose one option from the set of two on each table (e.g. Coke and Pepsi). For four of the nine choice pairs, one option was pre-tested to be healthier than the other (e.g. V8 or Hawaiian Punch, apples or brownies).

Half the participants made their choices in private while the other half made them in public. In the private condition, participants made their choices with no other participants in the room. In contrast, participants in the public condition made their choices when other participants were in the room. They were also told that the experimenter was interested in how people form impressions, and that after they made their selections, their choices would be given to another participant who would form impressions about them, at which point the two of them would interact. After following the cover story (participants saw another participants choices and formed impressions), participants were debriefed and were given an option they selected during the study.

\section{Results}

The number of junk food items each participant choose was summed to form a Junk Food Index (theoretical and actual range $=0-4$ ). A 2 (Similarity of Other Taste Holders: Similar vs. Dissimilar) x 2 (Visibility of Choice: Public vs. Private) ANCOVA was performed on the junk food index. ${ }^{4}$

As predicted, the analysis revealed a significant Similarity of Other Taste Holders $\mathrm{x}$ Visibility of Choice interaction, $F(1,54)=3.95, p=.05$, Figure 2 . When people made 
their choices in private, the similarity of the people associated with eating junk food did not significantly influence choice, $F<0.5, p>.60$. When choice was publicly visible, however, participants were less likely to select junk food when that behavior was associated with dissimilar others, $F(1,54)=4.99, p=.03$.

We also compared these cells to the control condition. Participants in this condition did not read any articles about junk food and thus can be considered a baseline. As expected, compared to the control condition, participants choose less junk food when that behavior was associated with dissimilar others and their choice was publicly visible, $t(69)=2.21, p=.03$. All other cells were equivalent to the control, $t \mathrm{~s}<0.5, \mathrm{ps}>.50$.

\section{Discussion}

Study 3 provides a strong demonstration that people diverge due to identitysignaling concerns by illustrating that people may diverge in public even when they do not do so in private. Participants were less likely to choose junk food when doing so was associated with dissimilar others, but only when other people viewed their choices. When their choices were private, outgroup association did not affect choice. These results help distinguish our identity-signaling perspective from optimal distinctiveness; if needs for differentiation were driving people to change their behavior in public, it is unclear why similar results did not occur when behavior was private.

The observed pattern of taste abandonment in Studies 2 and 3 are consistent with the notion that people may abandon tastes which are adopted by others that are dissimilar. It is worth noting though, that perceived similarity can be context-dependent. Italy and Switzerland may seem dissimilar in the context of other European countries, for example, but similar when compared to Brazil (Tversky, 1977). Similarly, the Academic and 
Target dorms, or undergraduates and graduate students, may seem very similar in the context of U.S. citizens as a whole, but dissimilar in the context of on-campus student groups. For these studies, the manipulation check and pretest verify that at least in the context of campus groups, our participants saw the outgroups as dissimilar.

One could potentially ignore the results of the ancillary data, however, and argue that our participants diverged in Studies 2 and 3 because the outgroups were so similar (e.g., similar age, part of the same university) that their identity was threatened. Further, one could argue that Study 3 confounds similarity with ingroup versus outgroup categorization. Though almost all prior intergroup research has used only a few levels of similarity, to more definitively examine the influence of similarity on divergence, one must examine a wider range of similarity.

Studies 4-7 do this. By examining groups that vary along a wide continuum of similarity, these studies address the potential concern that participants in Studies 2 and 3 diverged because the taste adopters could be seen as similar. In addition, Studies 4-6 include a number of groups which should be considered outgroups by our participants, and Study 7 explores groups explicitly nominated as outgroups by participants, so these studies allow us to tease apart similarity from ingroup versus outgroup categorization.

\section{Study 4: Abandonment Based on Outgroup Similarity, Status, and Liking}

In Study 4, people were asked how they would change their use of a cultural taste if it was adopted by various social groups (e.g., 40-yr old business executives, janitors, and suburban teenagers). Other participants rated the groups on similarity, liking, or demographic status. We predict that when their cultural taste is adopted by other social 
groups, people will diverge by decreasing their use of the catchphrase. Further, we predicted that divergence would be greater for groups that were rated as dissimilar. Importantly, our predictions differ from those made by some prior literature. Conformity predicts convergence, thus adoption by others might even lead people to increase their use. The status-focused sociological literature would predict high status groups should abandon tastes adopted by lower status groups, so people should only decrease their use of the phrase when it is adopted by others who have lower status; indeed adoption by higher status groups might lead people to increase their use of the phrase. Intergroup differentiation (at least on behavioral measures) predicts similarity should drive divergence. Finally, an explanation focused on liking would predict that people should imitate liked social groups (increasing their use of the phrase) and diverge from disliked social groups (decreasing their use of the phrase).

\section{Method}

\section{Taste Change Questionnaire}

Thirty-four Stanford undergraduates were told to imagine they and their friends liked to say a particular catchphrase that no one else was saying. Respondents were then asked what they would do $(-5=$ decrease their use, $5=$ increase their use $)$ if each of 15 social groups (Figure 3) started using the phrase. Taste change ratings were averaged across respondents to create a taste change index for each group $(\alpha=.73)$

\section{Group Ratings}

Separate sets of raters from the same population (total $\mathrm{N}=29$ ) rated the same social groups on one of three experimental measures. Some individuals rated outgroup similarity $(\alpha=.85)$ and others rated how their feeling towards the groups $(\alpha=.37)$. 
Additionally, to compare these ratings with sociological literature focused on macrodemographic status, the third set rated the groups on how society viewed the status of that group relative to them and their friends $(-3=$ Much Lower, $3=$ Much Higher, $\alpha=$ .97). Each of these measures was averaged across the set of participants and used to simultaneously predict taste change.

\section{Results}

As predicted, for 14 of the 15 social groups, respondents said they would be likely to abandon the catchphrase if other social groups adopted it (Figure 3). Respondents reported they would be most likely to decrease their use of the phrase if it was adopted by groups like 30 year old middle managers or janitors and least likely to abandon the phrase if it was adopted by Stanford athletes. A multiple regression then simultaneously tested how responses to imitation by another group (i.e. average taste change) varied based on average ratings of the similarity, liking, and status of that group.

While respondents were more likely to abandon a phrase the more the group adopting it was disliked, $\beta=.60, t(14)=2.51, p=.03$, consistent with identity-signaling, similarity of the adopting group predicted taste change, $\beta=0.55, t(14)=2.25, p=.05$.. Respondents were more likely to abandon the taste the more dissimilar the adopting group. Outgroup status did not predict abandonment, $\beta=-.37, t(14)=-1.53, p>.15 .^{5}$

\section{Discussion}

Study 4 provides further evidence of divergence: people suggested they would abandon a catchphrase when it was adopted by various outgroups. Further, consistent with identity signaling, abandonment was more pronounced for groups seen as dissimilar. The effect of similarity held even when we controlled for liking and demographic status. 
Prior theories have difficulty explaining these effects. Conformity would predict adoption by others should increase use of the phrase, not decrease it. Status, at least for this set of groups, did not predict divergence. Though literature on intergroup differentiation might predict divergence from extremely similar others, it is less useful in suggesting why people would diverge from dissimilar groups on a behavioral measurement like abandonment. Affect based predictions have difficulty explaining why people diverged even from groups that were generally liked.

\section{Study 5: Divergence to Avoid Confusion with Dissimilar Others}

Study 5 again examines whether people are more likely to diverge from dissimilar groups, but also whether this divergence is due to the desire to avoid being misidentified. Each participant rated the same groups used in the prior study on three measures: how they would change their taste if that group adopted it, outgroup similarity, and their desire to avoid being confused as a member. We predict that desire to avoid being seen as a member will mediate the relationship between outgroup similarity and divergence.

\section{Method}

Seventy-five Stanford students and staff completed three questionnaires. They

first rated much they would change their use of a catchphrase if it was adopted by each of 15 social groups (the taste change measure from Study 4). After completing a few filler tasks, they also rated the outgroup similarity and how much they would, or would not, want to be confused as a member of each group. The order of these two surveys was counterbalanced across respondents and separated by filler tasks. 


\section{Results}

Participants again reported they would decrease their use of the catchphrase if it was adopted by almost all of the social groups (14 of the 15). Because the data were nested with each participant rating 15 social groups, we tested the predicted relationship between similarity, desire not to be confused as, and divergence using hierarchical linear modeling in HLM (Raudenbush, Bryk, Cheong, \& Congdon, 2004).

Consistent with identity signaling, outgroup similarity predicted taste-change, $B=$ $0.25, t(75)=7.13, p<.0001 ;$ people were more likely to diverge from dissimilar outgroups. Outgroup similarity also predicted people's desire to avoid being confused as a member, $B=0.59, t(75)=14.88, p<.0001$; people preferred not to be thought of as akin to dissimilar outgroups. Moreover, the data confirmed the hypothesized mediational relationship. When both outgroup similarity and desire to avoid confusion were included as simultaneous predictors of divergence, the desire not to be confused as a member was linked to divergence, $B=0.28, t(75)=7.70, p<.0001$, and the relationship between outgroup similarity and divergence was reduced, $B=0.12, t(75)=3.25, p=.002$. A Sobel test confirmed that desire to avoid misidentification mediated the relationship between outgroup similarity and divergence, $\mathrm{z}=9.97, p<.0001$. Results were identical when outgroup liking and status (from Study 3) were included in the analyses.

\section{Discussion}

Results of Study 5 extend the findings of Studies 1 and 4 to a case where similarity, preference to avoid being thought of as a member, and divergence were measured within subjects. People reported that they would be more likely to diverge from groups they thought were dissimilar to themselves. They also reported preferring to avoid 
being confused with members of dissimilar social groups. Further, this preference mediated the relationship between similarity and divergence; people diverged, in part, to avoid being misidentified as an outgroup member.

\section{Study 6: Groups, Domains, and Abandonment}

Many domains of social life could be used to infer others' identity, but people tend to use certain areas more than others (Belk, 1981). Particular choices and attitudes have more symbolic functions (Shavitt, 1990) and people rely more on certain taste domains (e.g., cars, clothes, and music tastes rather than dish soap, stereo, and bike lights) when making inferences about others (Berger \& Heath, 2007).

We have argued that identity-signaling is a social process and, if this is true, then people should communicate using shared domains: Indeed, there is a high degree of consensus across individuals about which domains people use to express identity and infer others' identity, and further, these two sets of domain are highly correlated: people tend to express identity in the same domains that others use to infer identity (Berger \& Heath, 2007). Building on these findings, we suggest that if identity-signaling is driving divergence, then people should be most likely to diverge from dissimilar others in domains such as clothing or music that people regularly use to signal identity.

This prediction goes beyond existing theories of liking, status, or uniqueness. We may avoid groups we dislike or see as lower status, and we may have a greater need to differentiate ourselves when we feel overly similar, but these theories provide no explicit reason why we should do so in certain domains as opposed to others. It is also not clear how such a pattern could be explained by work on intergroup differentiation. ${ }^{6}$ 
The present study varied the similarity of the adopting group in a between subjects design to examine whether the threshold for taste abandonment differs based on both adopted similarity and whether or not the taste domain is related to identity. Students were given one of three social groups (which varied in similarity) and 10 different taste domains which varied in identity-relatedness (adapted from Berger \& Heath, 2007). Participants were asked to imagine that members of another social group had started to copy their tastes in a particular domain (e.g., Princeton students had started adopting their favorite type of music). They then indicated what percentage of that group would have to adopt the taste for them to abandon it. If divergence is driven by identity signaling concerns then the similarity of the adopting group should influence divergence, but only in domains that people use to communicate identity.

\section{Method}

One-hundred and thirty-two Stanford undergraduates were asked to imagine that they had a preference in each of 10 taste domains (e.g., hairstyle, cell phone brand) and that members of a certain social group had started copying their preference. For each domain, they were asked what percentage of the other group would have to copy their preference in order for them to consider abandoning it. Participants responded on a percentage scale from $10 \%$ to $100 \%$ (labeled "wouldn't abandon at any level”).

Conditions differed in the identity of the group adopting the participants' preferences. The groups were equivalently liked by Study 1 participants, but were seen as differing in their similarity to Stanford undergraduates - business executives (low similarity), inner city teens (moderate similarity) and Princeton students (high similarity). 
A separate set of raters from the same population $(\mathrm{N}=20)$ rated each domain based in how much others would use the domain to form inferences about their identity $(\alpha=.91)$.

\section{Results}

Hierarchical linear regression was used to test the hypothesized relationship between both similarity of the adopting group and identity-relatedness of the taste domain and the threshold required for taste abandonment. We first constructed a within subjects (level-1) linear equation that modeled how each participant responded to imitation by the other group depending on the identity-relevance of the taste domain in which the imitation occurred (from Berger \& Heath 2007). We also created a between-subjects (level-2) equation modeling how respondents' thresholds for abandonment differed as a function of the adopting group's similarity to the subject population. The MIXED procedure in SAS Version 8 was used to solve the equations. People provided the percentage of members in the adopting group that would have to copy their taste for them to abandon it, and thus lower numbers mean a lower threshold required for abandonment.

Figure 4 shows the level at which people would abandon tastes. Note that for nonidentity related items such as dish soap and DVD players, participants said that they would not abandon their preferred option even if $100 \%$ of the other group adopted it. The abandonment threshold decreased, however for tastes relevant to identity (e.g., music and jacket style). Our Stanford student participants said they would abandon a hairstyle used by $54 \%$ of business execs, or $72 \%$ of inner-city teens, or $71 \%$ of Princeton students.

As predicted, divergence varied by whether the domain was related to identity, $B$ $=-0.54, t(130)=-10.79, p<.0001$, and the similarity of the adopting group, $B=0.30$, $t(130)=2.34, p=.02$. When a cultural taste was more identity-related, participants 
required the presence of fewer others to abandon that taste. People also diverged most from the dissimilar outgroup. Finally, there was a significant domain identity-relatedness $\mathrm{x}$ outgroup similarity interaction, $B=0.10, t(130)=1.95, p=.05$. Outgroup similarity only influenced divergence in identity-related domains (e.g., the right side of Figure 4).

\section{Discussion}

Study 6 provides further evidences that identity-signaling drives divergence. In domains that are unrelated to identity, little (if any) divergence was observed, and outgroup similarity did not influence divergence. It was only in domains that others use to infer identity that outgroup similarity influenced divergence. In those domains, identity-signaling predicts that people will be wary of what their cultural tastes communicate about their identity, and they may abandon tastes that are adopted by other social groups (especially dissimilar ones) to avoid undesired identity inferences.

The fact that divergence was primarily observed in identity-related domains helps separate our identity signaling account from some alternative accounts. If balance theory or consistency based affect was leading people to diverge, they should do so for all products. If people merely wanted to be unique, they could do so by diverging in any area, but people seemed relatively happy to share their bike light and DVD player preferences with outgroup members.

One potentially puzzling result is the relative divergence between the three groups. Outgroup dissimilarity was linked to increased divergence overall, but examining the three groups separately reveals that people diverged slightly more from the similar than the moderately similar outgroup. It is a bit hard to interpret this result, however, given that only three social groups were used. Though they were liked equivalently, and 
differed in intergroup similarity, they also likely differ on a variety of other dimensions that may have influenced whether participants wanted to share tastes with them. Thus the final study uses a broader range of outgroups to provide a stronger test of the interactive effects of outgroup similarity and domain identity-relevance on divergence.

\section{Study 7: Outgroups, Domains, and Abandonment}

The first six studies provided evidence that people diverge from dissimilar others, in part because of the cost of being misidentified as a member of such groups. One could argue, however, that our participants did not diverge from similar groups because they did not consider them outgroups. Intergroup similarity can influence categorization, and superordinate categories may be more chronically accessible for similar social groups. This could lead people to see similar groups as ingroups rather than outgroups. But while we agree that people should only diverge if they see adopters as members of a separate social type with which they do not want to be confused, it is less clear that this alternative can explain our results. In Study 4, for example, it is possible that participants could have used superordinate categorization to categorize all "Stanford university members" as ingroup members, but among the remaining groups, the magnitude of the expected relationship between similarity and divergence still persists $(\beta=.49)$.

To further address this point, however, the final study uses only outgroups. Since one could argue that experimenter selected groups might actually be categorized as ingroups, we delegated group selection to our participants. Participants from a national internet sample listed a group they considered an outgroup. They were then asked how they would respond if that group adopted their tastes different domains. They also rated 
similarity, liking, status, and cost of being confused with the outgroup listed. Identitysignaling predicts that people should (1) diverge more from dissimilar outgroups, (2) that these effects should be more pronounced in domains people use to communicate identity, and (3) that the effects should be mediated by the cost of misidentification.

\section{Method}

One-hundred and sixty-three participants (Mean age $=32)$ were recruited through a nationwide web-survey database. Participants listed an outgroup (i.e., "a social group you do not consider yourself a member of") and this group was called Group Z for the rest of the study. They were then asked how they would respond if Group Z members started adopting their preference in various taste domains. They were asked to imagine that they and their friends had a preference in each of 16 domains (e.g., music artist, cell phone brand), and that Group $\mathrm{Z}$ members had started copying their preference (e.g., listening to the same artist or buying the same brand of cell phone). In each domain, participants then rated "how Group Z's adoption of your preference would affect your behavior" $(-3=$ decrease, $0=$ no change, $3=$ increase $)$.

Finally, before completing demographic measures, participants rated the outgroup on a variety of measures used in the prior studies. They were asked how similar the group was to them and their friends, how much they liked the group, and the status of the group. They also rated how costly it would be to be confused as a member.

\section{Results}

Participants provided a variety of outgroups such as Upper Class, Republicans, and Jocks. Hierarchical linear regression was again used to test the hypothesized relationship between outgroup similarity, domain identity-relevance, and taste change. 
As predicted, divergence varied based on the similarity of the adopting outgroup, $B=0.21, t(158)=2.00, p<.05$, and whether the domain was related to identity, $B=-$ $0.23, t(158)=-5.77, p<.0001$. Participants were more likely to abandon tastes if the outgroup adopters were dissimilar, and if the domain was identity-relevant. There was also a domain identity-relevance $\mathrm{x}$ outgroup similarity interaction, $B=0.08, t(158)=$ $3.50, p<.001$. Outgroup similarity predicted taste change more strongly in identityrelated domains. Neither outgroup liking, $B=0.12, t(158)=1.11, p>.25$, nor status, $B=$ $0.003, t(158)<0.1, p>.95$, provided additional predictive power in this instance.

In addition, results indicate that the effects of outgroup similarity on taste change were mediated by the costs of misidentification. Even controlling for liking and status, outgroup similarity was related to cost of misidentification, $B=0.20, t(160)=2.82, p=$ .005 , and both cost of misidentification, $B=0.60, t(158)=5.52, p<.0001$, and cost of misidentification $\mathrm{x}$ domain identity-relevance, $B=0.17, t(158)=5.78, p<.0001$, were related to taste change. Finally, when outgroup similarity and costs of misidentification were simultaneously entered in a regression predicting taste change, costs of misidentification was a significant predictor (main effect: $B=0.57, t(156)=5.18, p<$ .0001 , interaction with domain identity relevance: $B=0.16, t(156)=4.46, p<.0001$, whereas similarity dropped to insignificance (main effect: $B=0.09, t(156)<1, p>.35$, interaction with domain identity relevance: $B=0.02, t(156)<1, p>.55$. A Sobel test confirmed the significance of this mediational pattern, $\mathrm{z}=2.38, p=.01$.

\section{Discussion}

Results of Study 7 underscore the findings from the previous six studies. Using a broad set of groups considered outgroups by our participants, the results indicate that 
people diverge more from outgroups that are dissimilar. In addition, outgroup similarity was more predictive of divergence in domains that people use to infer others' identity. Finally, the mediational results demonstrate that people diverge from dissimilar others to avoid the increased costs of misidentification.

\section{General Discussion}

People often diverge from members of other social groups. They select cultural tastes that distinguish them from outgroup members and abandon tastes once they are adopted by other social groups. But while divergence is quite pervasive, little research has documented divergence or suggested a mechanism for this process.

Seven studies supported our identity-signaling perspective; people diverge to avoid signaling undesired identities. In addition, as predicted, people tended to diverge more from dissimilar others. In an initial demonstration, dorm members stopped wearing a wristband that was adopted by the dissimilar geeky dorm next door (Study 2). Greater divergence from dissimilar others again emerged when a broader range of social groups were used (Studies 4-7). People were also more likely to diverge from dissimilar others across a variety of domains (Studies 6-7). The results are consistent across both questionnaire data (Studies 4-7) and real choices (Studies 2 and 3).

The observed pattern of results also supports the notion that identity-signaling concerns drive divergence. We suggested that people would be more likely to diverge from dissimilar others because of increased costs of misidentification. Indeed, people suggested being confused with dissimilar others would have a more negative impact on their ability to interact with desired interaction partners (Study 1) and costs of 
misidentification mediated the influence of outgroup similarity on divergence (Study 7; also see footnote 5). Further support for our perspective comes from the fact that people diverged more in domains that people use to send and receive identity signals. Dissimilarity had a greater influence on divergence in domains that people use to communicate identity (Studies 6-7). Finally, the fact that people diverged in public, even when they did not do so in private (Study 2), helps distinguish identity-signaling from other theories (e.g., optimal distinctiveness), and underscores the notion that divergence is driven by concerns of outward communication.

Throughout these studies, identity-signaling adds to existing perspectives. People did not dislike the groups they diverged from, and similarity influenced divergence even when liking was controlled (Studies 4-7). Work on intergroup differentiation suggests that on behavioral measures, similarity drives differentiation, but these studies illustrated that people diverge more from others that are dissimilar. Status also did not predict divergence (Studies 4 - 7). Uniqueness and optimal distinctiveness suggest that internal needs drive differentiation, but they have difficulty explaining why public divergence would occur in the absence of private differentiation (Study 3). If people just diverged for affective consistency, they should do so equally in all domains. Instead, people seemed happy to share tastes with other social groups in certain domains (e.g., DVD player), but not in others (e.g., hairstyle, Studies 6-7).

The findings also highlight that identity-signaling is a social process. People tend to use taste domains like cars, clothing, and music to look for and send social identity signals, and these domains exist outside the power of any individual or group to alter. They are determined by the social system as a whole. 
Prior research related to domain differences has primarily focused on people distinguishing themselves in domains which have personal relevance for a particular group or individual. Group members sometimes differentiate themselves through selfstereotyping, for example, accentuating particular aspects of the self that are stereotypical of the ingroup (Pickett, et al., 2002). When honors students' distinctiveness is threatened, they rate themselves as more studious or intelligent (stereotype relevant traits), but not more loyal or helpful (stereotype irrelevant). Similarly, individuals care more about being unique in domains that are important to them personally (Campbell, 1986).

But idiosyncratic differences in stereotype relevance or personal importance are less useful in explaining why across groups people tend to diverge in certain domains (Studies 6-7). Different groups may have different idiosyncratic stereotypes, and particular individuals may find certain domains personally important, but across individuals and groups, people diverge more in domains that everyone uses to communicate identity (also see Berger \& Heath, 2007; Berger, Heath, \& Ho, 2008). Most honors students would not list clothing as personally important, and clothes are not particularly relevant to the group stereotype, but even so, they may abandon clothing tastes that are co-opted by outsiders because other people use that domain to make inferences about them. Rather than focusing on idiosyncratic variation or internal drives, we focus on the social construction and destruction of meaning and how tastes can communicate identity to others in the social world. 
Although our main finding was that people diverged more from dissimilar groups, there may be cases, beyond those we have studied in this paper, where people will diverge from similar others for signaling reasons, particularly when the likelihood of misidentification is high. When types are similar, there is likely greater taste overlap and they may be more likely to be confused with each other (Cooper \& Jones, 1966). Stanford students already look a lot like Princeton students: they wear similar clothes, listen to similar music, and come from similar socioeconomic backgrounds. Consequently, it is easier to confuse members of the two groups, and they may be particularly prone to diverge from one another in situations where correct recognition is desired, but confusion is likely (e.g., an intercollegiate summer program). Future research might manipulate the likelihood of confusion to examine how this influences divergence from similar others.

Further, as noted previously, the perceived similarity of a given group can vary based on the context (Turner, et al., 1987). Stanford students may generally see Princeton students as quite similar, but when put in a competitive context (e.g. an intercollegiate track meet), they may focus on points of difference and see the groups as more distant. The situation can also shift the level on which groups are categorized. Stanford students could see Princeton students as outgroup members, but if they shift to a superordinate categorization (e.g. students) they should see all university students as part of their ingroup. This manuscript examined the effect of similarity in a particular context on divergence in that context, but if the context was manipulated, or a different context used, the perceived similarity of a particular group might vary. Importantly, however, regardless of how similar people perceive a particular group, the role that 
similarity plays in divergence should be the same: people should diverge more from groups they see as dissimilar.

Other factors beyond similarity may also influence divergence; identitysignaling predicts that how people respond to others adopting their tastes will depend on whether they want to be thought of as members of that group. People should abandon tastes adopted by stigmatized groups to avoid sending undesired identity signals. (Indeed, in Study 4, a measure of average attitudes towards a particular group was related to taste change.) By the same token, identity-signaling predicts that people will continue using tastes adopted by aspiration groups (Englis \& Solomon, 1995), or other social groups they want to look like. How people react to others adopting their tastes may also depend on the domain. If a certain group is seen as having expertise or trend setter status in a given domain, others should be less likely to abandon tastes that this group adopts in that domain.

\section{Identity Signaling and Related Literatures}

These findings contribute to the burgeoning literature on the propagation and success of cultural tastes (e.g., Berger, in press, Berger \& Heath, 2005; Kashima, 2000; Lyons \& Kashima, 2003; Schaller \& Crandall, 2004; Schaller, Conway, \& Tanchuk, 2002) by examining a process that influences how tastes spread. While models of diffusion of innovations and cultural tastes (e.g., Bass, 1969; Latane, 1996; Rogers, 1983) show that people often converge to the behavior of others, there are also many cases where people diverge from other social groups. In these cases, adoption by others may lead the original taste holders to abandon the taste. Thus processes of conformity and imitation may lead tastes to spread rapidly within social groups, but processes of 
divergence may prevent cultural tastes from being widely held among the population at any given time (see Berger, in press).

Our perspective highlights the importance of attending to the meaning associated with a cultural taste. For tastes that act as signals of identity, what engaging in a practice signals depends on who else is engaging in it, and consequently, meaning is dynamic. Such shifts in the meaning often occur when outsiders adopt others' tastes but can also shift through interventions which link tastes to particular social identities. Further, because people adopt or abandon behaviors not only for their functional value, but also based on what they communicate, such manipulations can have pro-social effects. Linking a dissociative outgroup to binge drinking, for example, both shifted the identity associated with drinking and reduced alcohol consumption (Berger \& Rand, 2008).

This paper has focused on why people diverge when their tastes are poached by outsiders, but more research is necessary to examine why outsiders poach the tastes of others in the first place. People often want others to identify and treat them like the type of person they actually are, but sometimes they may want to be treated as members of other groups, and to reach this goal, may poach the cultural tastes of those groups (e.g., Berger, Heath, \& Ho, 2008). Researchers know little about the poaching portion of the process. To truly understand both the spread and decline of cultural tastes, we need to understand both processes of imitation and divergence. 


\section{References}

Abrams, D. \& Hogg, M. A. (1988). Comments on the motivational status of self-esteem in social identity and intergroup discrimination. European Journal of Social Psychology, 18, 317-334.

Asch, S. E. (1956). Studies of independence and conformity: A minority of one against a unanimous majority. Psychological Monographs, 70 (Whole no. 416).

Banerjee, A.V. (1992). A simple model of herd behavior. Quarterly Journal of Economics, 107, 797-817.

Bass, F. M (1969). A new product growth model for consumer durables. Management Science, 13, 215-227.

Belk, R.W., Bahn, K.D., \& Mayer, R.N. (1982). Developmental Recognition of Consumption Symbolism, Journal of Consumer Research, 9, 4-17.

Berger, J. (in press). Identity-signaling, social influence and social contagion. In M. J. Prinstein \& K. A. Dodge (Eds), Understanding peer influence in children and adolescents. New York: Guilford.

Berger, J \& Heath, C. (2005). Idea Habitats: How the Prevalence of Environmental Cues Influences the Success of Ideas. Cognitive Science, 29(2), 195-221.

Berger, J. \& Heath, C. (2007). Where consumers diverge from others: Identity-signaling and product domains. Journal of Consumer Research, 34, 121-134.

Berger, J., Heath, C., \& Ho, B. (2008). Divergence in cultural practices: Tastes as Signals of Identity. Working paper. 
Berger, J. \& Rand, L. (2008). Shifting signals to help health: Using identity-signaling to reduce risky health behaviors. Journal of Consumer Research.

Escalas, J. E. \& Bettman, J. R. (2005). Self-construal, reference groups, and brand meaning. Journal of Consumer Research, 32, 378-89.

Bourdieu, P. ([1979] 1984). Distinction: A Social Critique of the Judgment of Taste, translated by Richard Nice. Cambridge, Mass: Harvard University Press.

Brewer, M. (1991). The social self: On being the same and different at the same time. Personality and Social Psychology Bulletin, 17, 475-482.

Brown, R. J., \& Abrams, D. (1986). The effects of intergroup similarity and goal interdependence on intergroup attitudes and task performance. Journal of Experimental Social Psychology, 22, 78-92.

Bryson, B. (1996). Anything but heavy metal: Symbolic exclusion and musical dislikes. American Sociological Review, 61, 884-899.

Campbell, J. D. (1986). Similarity and uniqueness: The effects of attribute type, relevance, and individual differences in self-esteem and depression, Journal of Personality and Social Psychology, 50, 281-294.

Cialdini, R. B., R. J. Borden, A. Thorne, M. R. Walker, S. Freeman, \& L. R. Sloan (1976). Basking in reflected glory: Three (football) field studies. Journal of Personality and Social Psychology, 34, 366-375.

Clevstrom, J. \& Passariello, C. (2006). No kicks from 'Chavpagne.' The Wall Street Journal, August 18, A11. 
Cohen, G. L. \& Prinstein, M. J. (2006). Peer contagion of aggression and health-risk behavior among adolescent males: An experimental investigation of effects on public conduct and private attitudes. Child Development, 77, 967-983.

Cooper, J., \& Jones, E.E. (1969). Opinion divergence as a strategy to avoid being miscast. Journal of Personality and Social Psychology, 13, 23-30.

Davis, F. (1992). Fashion, Culture and Identity. Chicago: Chicago University Press.

DiMaggio, P. (1982). Cultural entrepreneurship in nineteenth-century Boston: The creation of an organizational base for high culture in America. Media, Culture and Society 4, 33-50.

DiMaggio, P., \& Powell, W. (1983). The iron cage revised: Institutional isomorphism and collective rationality in organizational fields. American Sociological Review, 48, $147-$ 160.

Douglas, M., \& Isherwood, B. (1978). The World of Goods: Towards an Anthropology of Consumption. New York: W.W. Norton.

Englis, B.G. \& Solomon, M.R. (1995). To be and not to be? Lifestyle imagery, reference groups, and the clustering of America. Journal of Advertising, 24, 13-28.

Ganster, D., McCuddy, M., \& Fromkin, H.L. (1977). Similarity and undistinctiveness as determinants of favorable and unfavorable changes in self-esteem. Paper presented at the Midwestern Psychological Association, Chicago.

Harton, H. C., \& Bourgeois, M. J. (2004). Cultural elements emerge from dynamic social impact. In M. Schaller \& C. S. Crandall (Eds.), Psychological foundations of culture (pp. 41-75). Hillsdale, NJ: Erlbaum.

Hebdige, D. (1987) Subculture: The Meaning of Style, London: Routledge. 
Heider, F. (1946). Attitudes and cognitive organization. Journal of Psychology, 21, 107112.

Hogg, M. A. (2000). Subjective uncertainty reduction through self-categorization: A motivational theory of social identity processes. European Review of Social Psychology, 11, 223-255.

Jackson, L. A., Sullivan, L. A., Harnish, R., \& Hodge, C. N. (1996). Achieving positive social identity: Social mobility, social creativity, and permeability of group boundaries. Journal of Personality and Social Psychology, 70, 241-254.

Jetten, J. \& Spears, R. (2003). The divisive potential of differences and similarities: The role of intergroup distinctiveness and intergroup differentiation. European Review of Social Psychology, 14, 203-241.

Jetten, J., Spears, R. \& Postmes, T. (2004). Intergroup distinctiveness and differentiation: A meta-analytic integration. Journal of Personality and Social Psychology, 86, 862879.

Latane, B. (1996). Dynamic social impact: The creation of culture by communication. Journal of Communication, 46(4), 13-25

Levy, S. J. (1959). Symbols for sale. Harvard Business Review, 33, 117-124.

London, A.S., \& Morgan, S. P. (1994). Racial differences in first names in 1910. Journal of Family History, 19, 261-284.

Lynn, M. \& Snyder, C.R. (2002). Uniqueness seeking. In: C.R. Snyder and S.J. Lopez (Eds.), Handbook of positive psychology, Oxford University Press, London, 395-410. 
Lyons, A. \& Kashima, Y. (2003). How are stereotypes maintained through communication? The influence of stereotype sharedness. Journal of Personality and Social Psychology, 85, 989-1005.

McIntyre, A., Lyons, A., Clark, A., \& Kashima, Y. (2004). The microgenesis of culture. In M. Schaller \& C. Crandall (Eds.), The psychological foundations of culture. Mahwah, NJ: Erlbaum.

Mlicki, P., \& Ellemers, N., (1996). Being different or being better? National stereotypes and identifications of Polish and Dutch students. European Journal of Social Psychology, 26, 97-114.

Moghaddam, F.M. \& Stringer, P. (1988). Outgroup similarity and intergroup bias. Journal of Social Psychology, 128, 105-115.

Muller, D., Judd, C. M., \& Yzerbyt, V. Y. (2005). When moderation is mediated and mediation is moderated. Journal of Personality and Social Psychology, 89, 852-863.

Mummendey, A., \& Schreiber, H. J. (1984). “Different” just means “better”: Some obvious and some hidden pathways to ingroup favoritism. British Journal of Social Psychology, 23, 363-368

Norenzayan, A., Atran, S., Faulkner, J., \& Schaller, M. (2006). Memory and mystery: The cultural selection of minimally counterintuitive narratives. Cognitive Science, 30, $531-553$.

Pickett, C.L., Bonner, B.L., \& Coleman, J.M. (2002). Motivated self-stereotyping: Heightened assimilation and differentiation needs result in increased levels of positive and negative self-stereotyping. Journal of Personality and Social Psychology, 82, $543-562$. 
Raudenbush, S. W., Bryk, A. S., Cheong, Y. F., \& Congdon, R. (2004). Hierarchical Linear and Nonlinear Modeling (Version 6.01a) [Computer software]. Lincolnwood, IL: Scientific Software International.

Robinson, D. E. (1961). The economics of fashion demand. Quarterly Journal of Economics, 75, 376-398.

Roccas, S., \& Schwartz, S.H. (1993). Effects of intergroup similarity on intergroup relations. European Journal of Social Psychology, 23, 581-595.

Rogers, E.M. (1983). Diffusion of Innovations. New York: The Free Press.

Rubin, M. \& Hewstone, M. (1998). Social identity theory's self esteem hypothesis: A review and some suggestions for clarification. Personality and Social Psychology Review, 2, 40-62.

Schaller, M., Conway, L. G., III, \& Tanchuk, T. L. (2002). Selective pressures on the once and future contents of ethnic stereotypes: Effects of the communicability of traits. Journal of Personality and Social Psychology, 82, 861-877.

Schaller, M. \& Crandall, C. S. (2004). The psychological foundations of culture. Mahwah NJ: Lawrence Erlbaum Associates.

Shavitt, S. (1990). The role of attitude objects in attitude functions. Journal of Experimental Social Psychology, 26, 124-148.

Sherif, M. (1936). The Psychology of Social Norms. New York: Harper.

Simmell, G. ([1904] 1957). Fashion. American Journal of Sociology, 62, 541-548.

Snyder, C.R., \& Fromkin, H.L. (1980). Uniqueness, New York: Plenium. 
Spears, R., Jetten, J., \& Scheepers, D. (2002). Distinctiveness and the definition of collective self: A tripartite model. In A. Tesser, J.V. Wood, \& D.A. Stapel (eds.). Self and motivation: Emerging psychological perspectives (pp. 147-171). Lexington:APA.

Sproles, G. B. (1985). Behavioral science theories of fashion. In M. R. Solomon (ed.). The Psychology of Fashion (pp. 55-70). Lexington: D. C. Heath/Lexington Books.

Swann, W. B. Jr. (1983). Self-verification: Bringing social reality into harmony with the self. In J. Suls \& A. G. Greenwald (eds.), Psychological Perspectives on the Self (pp. 33-66), Hillsdale: Erlbaum.

Tajfel, H. (1982). Social identity and intergroup relations. Cambridge, England: Cambridge University Press

Tajfel, H., \& Turner, J. C. (1979). An Integrative Theory of Intergroup Conflict. In W.G. Austin \& S. Worshel (Eds.), The Social Psychology of Intergroup Relations. Monterey: Brooks/Cole.

Thornton, S (1995). Club Cultures: Music, Media and Subcultural Capital. Cambridge and Oxford: Polity Press.

Turner, J. C. (1978). Social categorization and social discrimination in the minimal group paradigm. In Tajfel, H. (Ed.), Differentiation between social groups: Studies in the social psychology of intergroup relations. London: Academic Press, 101-140.

Turner, J. C., Hogg, M. A., Oakes, P. J., Reicher, S. D., \& Wetherell, M. S. (1987). Rediscovering the Social Group: A Self-Categorization Theory. Oxford: Blackwell. Tversky, A. (1977). Features of similarity. Psychological Review, 84, 327-352. 
Vignoles, V. L., Chryssochoou, X., \& Breakwell, G. M. (2000). The distinctiveness principle: Identity, meaning, and the bounds of cultural relativity. Personality and Social Psychology Review, 4, 337-354.

Walker, R. (2004). Yellow fever: What happens when philanthropy and style team up? A charity craze. New York Times Magazine, August, 9, 23.

Wernerfelt, B. (1990). Advertising content when brand choice is a signal. Journal of Business, 63(1), 91-98.

White, K. and Dahl, D. (2006). To be or Not be? The influence of dissociative reference Groups on Consumer Preferences. Journal of Consumer Psychology, 16(4), 404-414

White, J.B., \& Langer, E.J. (1999). Horizontal hostility: Relations between similar minority groups. Journal of Social Issues, 55, 537-559.

Wonacott, P. (2004). China's Buick infatuation: The stodgy American auto is a prerevolutionary icon for booming middle class. Wall Street Journal, 22 July, B1. 
Author Note

Jonah Berger, The Wharton School, University of Pennsylvania; Chip Heath, Graduate School of Business, Stanford University.

This article is based on a portion of the first author's doctoral dissertation. The research was supported by funding from Stanford's Graduate School of Business. We are grateful to Jennifer Aaker, Marilynn Brewer, Ben Ho, Jolanda Jetten, Jonathan Levav, Wendy Liu, Noah Mark, Annalisa Mastri, Cynthia Pickett, Baba Shiv, Itamar Simonson, and Christian Wheeler for their helpful comments on different versions of the research. Portions of the research were presented at the 2007 annual meeting of the Society for Personality and Social Psychology and the 2006 annual meeting of the Association for Consumer Research

Correspondence concerning this article should be addressed to Jonah Berger, 700

Jon M. Huntsman Hall, 3730 Walnut Street, University of Pennsylvania, Philadelphia, Pennsylvania, 19104-6340. Email: jberger@wharton.upenn.edu. 
Figure 1: Livestrong Wristband and Study Timeline

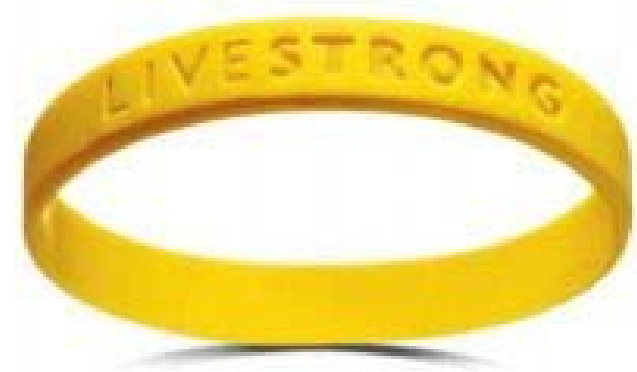

Sold wristbands to Target and Control dorms

(Time 1)

Sold wristbands to

"Geeky" dorm

(Time 3)

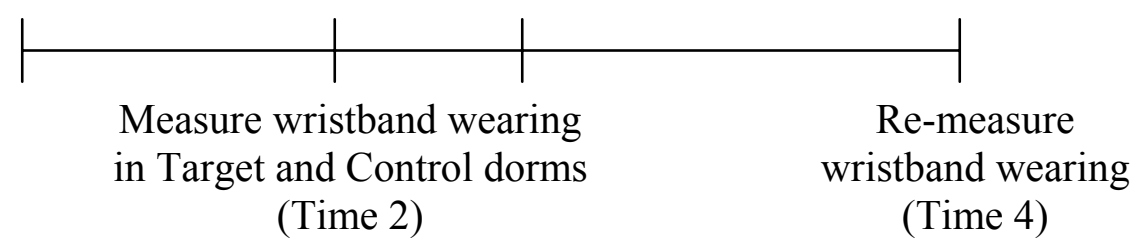


Figure 2: Influence of Similarity of Other Taste Holders and Public Visibility of Behavior on Taste Change

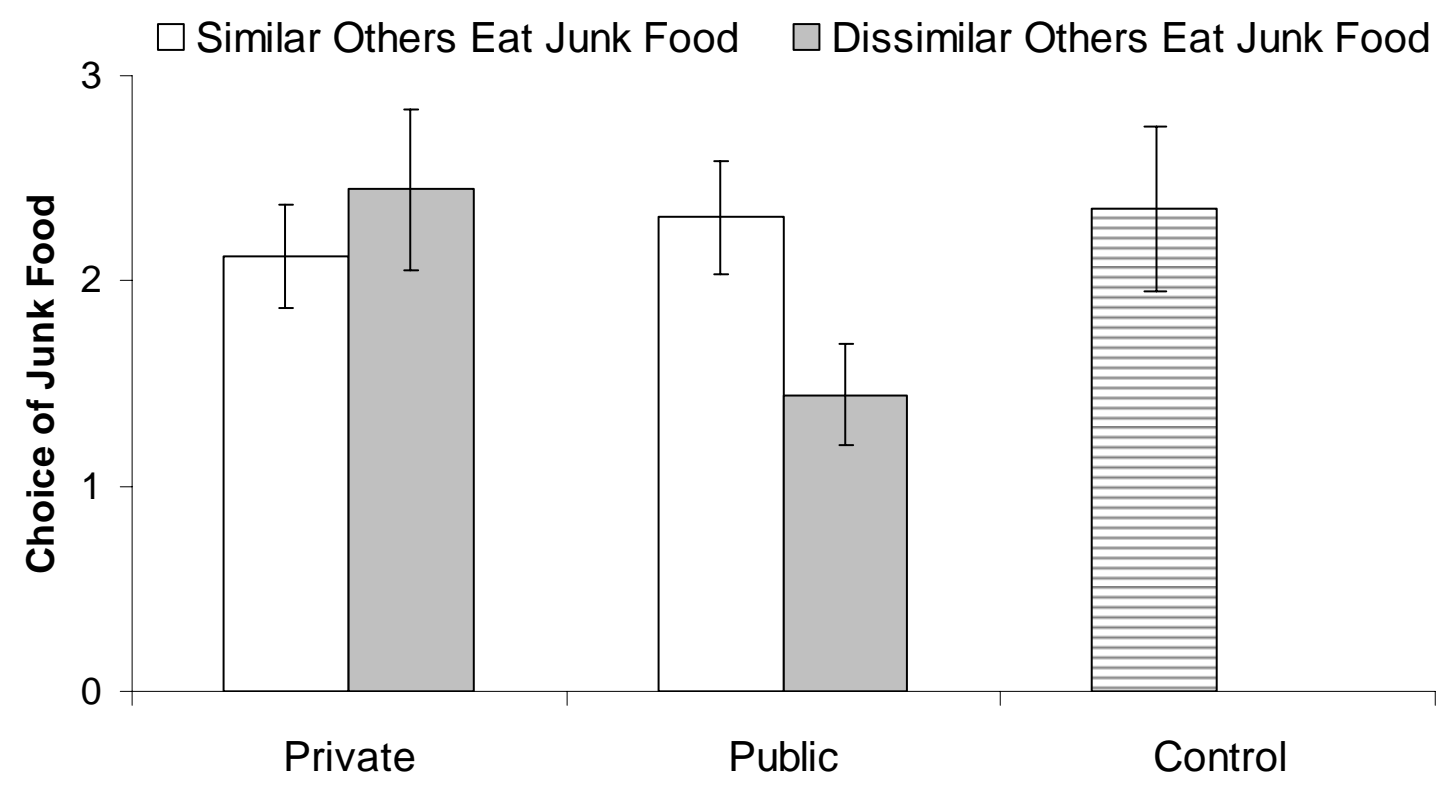


Divergence and Identity-Signaling 54

Figure 3: Change in Taste Expression Based on Similarity of the Adopting Group

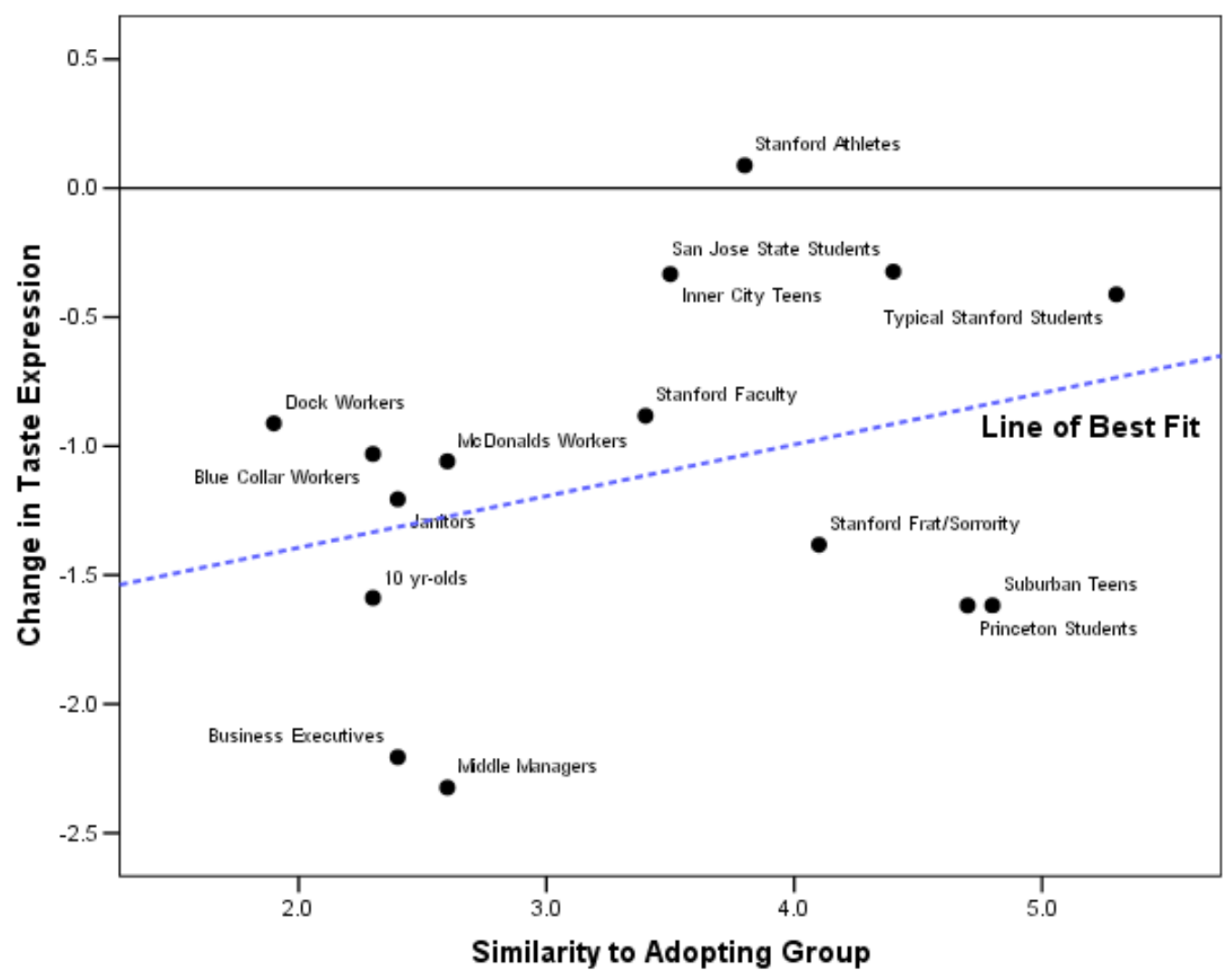


Figure 4: Divergence Threshold Based on Similarity of Adopters and How Related the Taste Domain is to Identity

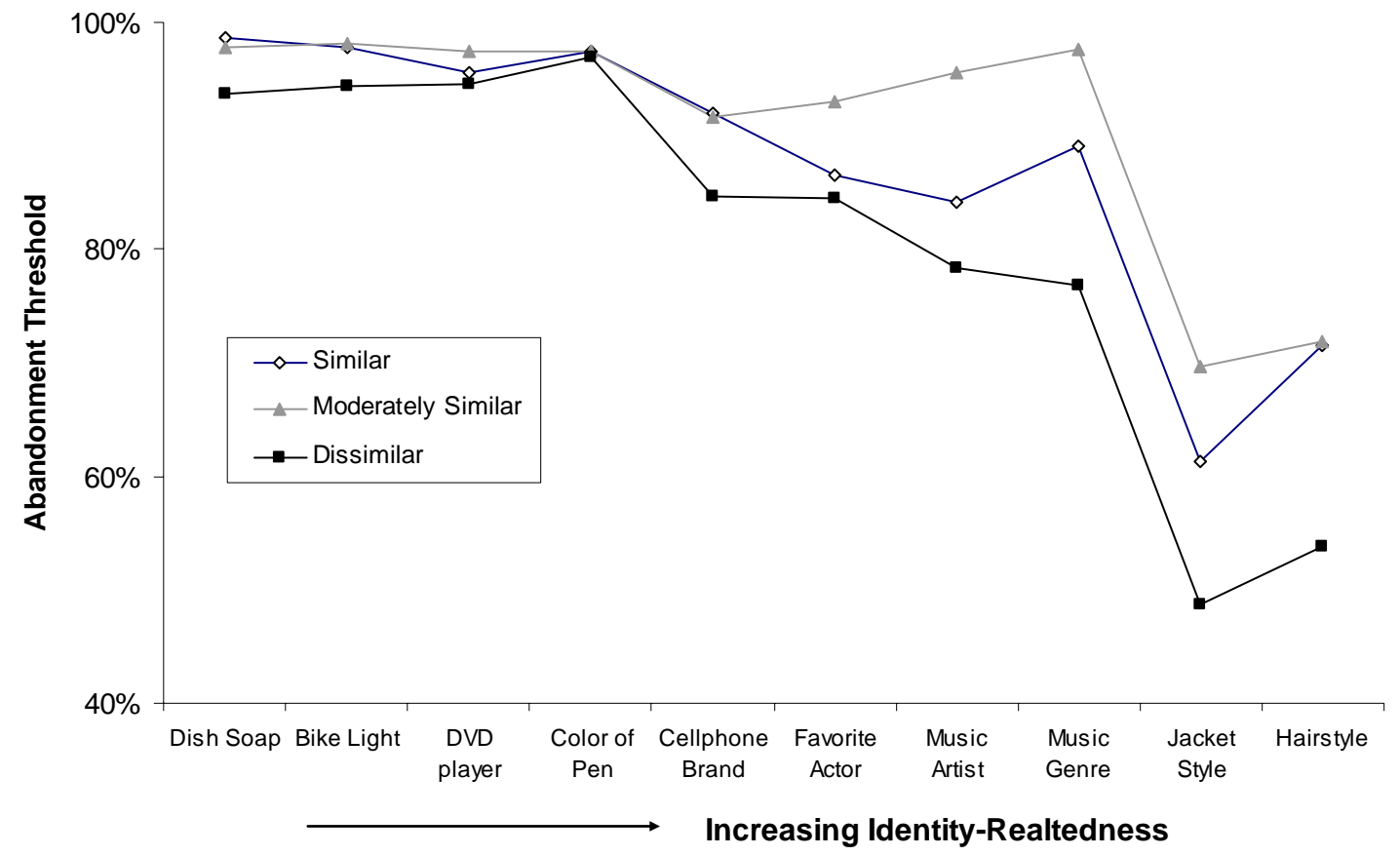




\footnotetext{
${ }^{1}$ Members of the different dorms were similar: all were freshman only and none had any particular academic focus.
}

${ }^{2}$ We used food choice because prior research found that it is considered identity-relevant (Berger $\&$ Heath, 2007). When people rated how much they use different domains in self-expression $(1=$ not self-expressive, $7=$ very self expressive $)$ or to infer things about others $(1=$ not at all used to make inferences about others, $7=$ frequently used to make inferences about others) food choice was rated above the midpoint on both scales $(\mathrm{M}=4.67, \mathrm{t}(14)=2.32, \mathrm{p}<.04 ; \mathrm{M}=4.81, \mathrm{t}(15)=$ $2.56, \mathrm{p}=.02)$.

${ }^{3}$ Participants rated 18 campus groups (e.g., graduate students and faculty members) on either liking or similarity (scales from Study 1$)$. Graduate students were seen as dissimilar $(M=2.67$, significantly below the scale midpoint, $t(14)=3.01, p<.01$ and in the bottom quarter of the groups listed), but were not disliked $(M=.90$, significantly above the scale midpoint, $t(33)=$ $4.96, p<.001)$.

${ }^{4}$ Whether the sessions were conducted before or after lunch influenced food choice $\left(M_{\text {before }}=1.72\right.$ vs. $\left.M_{\text {after }}=2.35, F(1,54)=3.79, p=.06\right)$ and was included as a covariate in the analysis.

${ }^{5}$ There are issues with trying to claim mediation using only measured variables (Muller, Judd, \& Yzerbyt, 2005), but it is worth noting that when combined with the data from Study 1, the pattern of results are at least consistent with the notion that misidentification costs mediate the relationship between outgroup similarity and divergence. Even controlling for liking and status, when misidentification costs are included in the regression with similarity, the costs of misidentification emerges as a significant predictor of taste change $(\beta=.83, t(14)=2.52, p=.03)$ whereas outgroup similarity drops to insignificance $(\beta=-.23, t(14)=-0.91, p>.35)$.

${ }^{6}$ Prior literature (Tajfel \& Turner, 1979) suggests that the relationship between distinctiveness and differentiation may be moderated by "the relevance of the dimension of comparison in a particular intergroup setting" (Jetten, et al., 2004, p.864), but a meta-analysis coding for general relevance found no evidence of this moderator (Jetten, et al., 2004). 